\title{
The Problems and Solutions Existing in the Autonomous Learning under the Network Environment
}

\author{
Lirong $\mathrm{Ma}^{1, a}$, Xuefeng $\mathrm{Li}^{2}$, Zhuang $\mathrm{Su}^{1}$ \\ ${ }^{1}$ Information Management Centre of Flight Fundamental Training Base ,Aviation University of \\ Air Force, Chang Chun, 130022, China \\ ${ }^{2}$ Flight Fundamental Training Base, Aviation University of Air Force,Chang Chun, \\ 130022, China \\ aemail: malirong2000@163.com
}

Keywords: Network Environment; Autonomous Learning

\begin{abstract}
The development of network technology make network education become possible and quickly popularize, the network education resources largely changed the traditional education mode. This paper first introduces the concept of autonomous learning under the network support, it is expounded for the students that learning environment and learning style are changed, and put forward solution measures which the problems existing in the current network autonomous learning.
\end{abstract}

\section{Introduction}

The rapid development of science and technology, especially the wide application of information technology brings human into a new knowledge economy era. In order to cultivate new talents to adapt to the new time request, a new round of education reform is set off around the world: lifelong learning and autonomous learning has become the ultimate goal of education reform. National higher education section puts forward the guidance with the teaching model reform in 2004, namely "the colleges should make full use of multimedia and network technology, adopt a new teaching mode, improve the original single classroom teaching mode, new teaching model should be based on modern information technology, especially the network technology as support, make the teaching is not restricted by time and place, develop in the direction of individualized learning and autonomous learning.

\section{Autonomous Learning under the Support of Network}

Autonomous learning refers to students autonomous learning with the modern computer network support. Autonomous learning is characterized of self-managed learning, autonomous learning is not affected by time and space limit. Learners for their own learning activity plans and arrangements in advance; They monitor, evaluate and feedback in the practical learning activity; they also adjust, modify and control their own learning activities. Autonomous learning is initiative, feedback, regulatory, mobility, validity and other features. And autonomous learning under the network environment, not only has the advantages above all but also expand the object and scope of this model, provides a new way of learning environment and mode.

\section{A. The change of learning environment}

Compared with the traditional learning environment, multimedia network environment has the essential characteristics and advantages.

Interactivity: multimedia network can provide an interactive platform, resource, teachers, students, curriculum and multimedia technology can integrate a new network time and space environment. Implements the "teacher -student interaction; student - student interaction; student learning resources interaction". In such an interactive platform, students can institute learning goals, choose learning content, control learning process, participate in the activities of teaching according to their needs, multimedia is not only a learning tool, but also a teacher, prompting, guide students 
to explore, to find, and greatly improve the learning interest of the students.

Integration: the greatest characteristic of multimedia network teaching is its integration, resource integration and learning environment integration. On the data collection, students can integrate information from multiple channels by use of network.

Self-adaptability: multimedia network teaching emphasizes students' subjectivity, based on students individual differences, students can determine the learning objectives, learning content, learning progress according to their own self adaptive principle; even choose learning methods and skills; Monitor the learning process, evaluate learning outcomes.

Autonomy: the multimedia network teaching is solely based on students as the center, the student enjoys a completely autonomous learning environment. The student have complete control of learning materials, learning content, learning speed and learning method. Teacher is the guide, collaborators, supervisors of study; students become dominant during the study.

\section{B. The change of study way}

Traditional way of learning is a typical "cramming" teaching, teachers lecture with a book, a piece of chalk and a blackboard; students study with a pen and a notebook. Students are completely in a passive form, they passively accept knowledge. Network information technology provides students with full autonomy and space, students have sufficient freedom in learning, completely broke the shackles of the teachers, students' learning is independent and innovation.

Application of information network has changed the traditional teaching process in the "teacher-student" interactive mode. It will appear "teacher-media-students" interactive mode, so that the teachers play the traditional role as the owners, the messengers, the symbol of the knowledge reduced; teachers play the role as the guidance for the student, class designer and theoretics explainer progressive enhance. Teachers will change the mode in imparting to knowledge as major tasks and memory knowledge as a result, focus on teaching from "teaching" to "Guide", from "result" to "process" ,from "knowledge" to "capacity". The relationships between teachers as a provider of knowledge and students as a learning has changed from traditional and one-way communication to interactive communication. Under the information network environment, students are learning main body, each student will have their own unique way of thinking and problem-solving methods. The learning of students no longer make reciting as the purpose, but in the pursuit of learning capacity, the pursuit of self creating and constantly updating knowledge as the destination.

Traditional education is a standardized education, students are volume-produce with the unified goal, specifications, standards, planning. The educatee is shaped into a standard product with the guide of unified teaching outline in a unified $\mathrm{f}$ time, space, speed and process.

Autonomous learning under the network information technology is a personalized learning , students can design learning objectives, select learning content, adjust the learning process, collection of learning materials follow their own interests, hobbies , and learning ability independent of time, space, resources, it can maximize develop the students' own personality .

Traditional education is a closed education, it has the unified purpose, the same textbook, the same teachers, the aptotic time, the centralized location, the orderly teaching content ,the ponderous teaching methods, students have not the free development space. Teaching under the network is an open teaching, it form a equal two-way relationship, such as " man - machine " relationship, " man - machine - man" relationship, learners have greater freedom of movement space, learning content is not limited to the books, learning spaces are no longer limited to the classroom, learning time is no longer limited to the period, breaking the geographical and time boundaries .

The information sources which students obtain is single in traditional classroom, they can only obtain from the teachers and textbooks, learning form is single only listening to teachers explain. The teaching content which is designed by the network information technology is hypertext learning materials such as sound, text, animation, it make education more open and pluralistic . Hypertext structure is conducive to students' divergent thinking and creative thinking, especially for students " self-discovery, self- discovery- learning ". 
Teaching under the network environment is a dynamic process. Network Information Technology provide the dynamic learning resources and learning environment integration text, animation. In this learning environment, teachers and students can form a dynamic interaction. In addition to traditional interaction between teachers and students, students and students, students and learning resources in the network environment also can interact at the same time. Students can also send BBS online, exchange of information, exchange of learning resources and learning experience, etc. These are not the advantage of the traditional classroom.

\section{The Problems and Solutions Exiting in the Current Network Autonomous Learning}

A. Network autonomous learning has irreplaceable advantages of traditional classroom teaching , but it still has some problems to be solved immediately in the actual network teaching process.

1) Over-reliance on network technology, network communication instead of traditional interaction of teachers and students.

Classroom teaching under multimedia network environment have three forms of interaction: teachers and students interact with the computer, students interact with teachers face to face, students interact with students face-to-face. Teachers in the implementation attach importance to the first interaction while ignoring the last two interaction, so that make the interaction between teachers and students, students and students from direct interaction into indirect interaction.

2) The students incept the online information in a single way, lack of depth thinking.

Because computer transmit information in fast paced, large capacity, so classroom teachers tend to use it to provide students with a lot of emotional material. Students spent a lot of time watching the screen and operating the mouse. Multimedia screen frequency transform, dizzying, but the thinking is in a dormant state or only superficial, this teaching is a new form of injection teaching.

3) Curriculum integration attach importance to the technology and ignore the dominant position of curriculum.

The use of information technology should be integrated in the disciplines teaching, information technology serve disciplines teaching, cultivate students the information diathesis, that is the integration of information technology and subject which is the education experts expect. However, some teachers attach importance to the information technology and ignore the objectives of disciplines teaching while implementing the curriculum integration.

4) Excessively open in the network teaching, the teachers are in inaccurate role.

Teaching resources are open under network support classroom, teaching tool is open , research direction is open, the exchange and evaluation is open , the advent of the Internet really provides us an open learning environment, greatly enriched the classroom form. Some teachers grasp his role is not in place, resulting in the teaching process excessively open, many students in the classroom " research without rhyme or reason " , " muddleheaded online learning " , " endless discussion ", Finally teachers have to hurry remediation .

5) Network autonomous learning reflects the individualized learning, ignore the report and sharing of the student learning outcomes.

Some of the teachers lack of effective constraint strategies for autonomous learning in the network environment : Students are attracted in wonderful network information, focus on practical operation and personal learning experience, make the interaction, the cooperation and the testing session just a formality ; at the same time, the most direct consequence which overfull emphasis on students' individual learning is that students deviate important objective of teamwork spirit training and collaborative problem-solving ability .

\section{B. Solution}

1) Teachers should right treat the network communication.

Teacher in classroom teaching should not give up easily the opportunities that direct face-to-face interact between teachers and students, use sparingly the communications and be good at using the communications according to the teaching objectives and contents . 
2) Teacher should fully take into account the teaching objectives before teaching, appropriate choice the materials, and preserving the material itself is instructive, inspiring students 'thinking.

It should also full play to the leading role of teachers, and utilizing the network information establishes the problem scenario, designing depth and challenging question, active students ' thinking, and mobilizing students potential and learning motivation, so that network ultimately improve the teaching quality and efficiency .

3) It is using the tools for teaching purposes, rather than to using the tool for teaching while information technology teaching.

Teachers should integrate the information technology into the curriculum. Information technology and curriculum integration should return to the course itself, and not replace the existing subject content of the information technology itself.

4) We should grasp the scale of open and close measure in the network teaching

Teachers should played several role while let the students to tries to and research: problem situation designers (design the task which contact with the students life, rich challenging and value of research), and information offer (avoid students no aim online), and cooperation division guider (reasonable arrangements division within group, improve learning efficiency), and research process promoter (make students not deviated from initial learning target, help students research problem in depth), and interact feedback Organizer (make the interaction in right direction), outcome evaluation participants (make the students gain by study).

5)We should attach importance to carrying out extensive interaction, competition and cooperation between students and teachers while emphasis on network individualized learning, especially emphasis the show and report of the results

Let students use appropriate technology, correctly express their views, make student find their own inadequacies in the interaction, promoting deeper reflection on the problems in the interaction, sharing the joy and outcomes of learning with the students, raising the value of learning.

\section{The conclusion}

In short, there is some problems in improving the students' autonomous learning ability by use of the network educational resources, as long as we are good at finding problems and solutions quickly, the network resources can really play a proper education function.

\section{References}

[1] Hongxia Zhang. Network Education Research Actuality in Our Country [J]. Beijing Post and Telecommunications University Transaction, 2006 ( 2 ).

[2] Bo BI.Autonomous Learning in the Network Environment[J] . Primary and secondary School Education with Electrical Audio-visual Aids, 2003 (3).

[3] Hongjun Cheng, Hongxia Cheng. Exploring in Teaching Mode in Net Environment [J].Henan: Fujian Computers, 2007(04).

[4] Jun Wu. Comparison Analysis between Net Teaching and Classroom Teaching [J]. China Education with Electrical Audio-visual Aids, 2007 (05).

[5] Guoying Zhang. The Essence of Remote-net Teaching and Study-guide Strategy of Net-type Teacher[J].Computer Education, 2008 (9).

[6] Yunfeng Lu, The Study on Informationalized Education in Military Academies [M] . Beijing: PLA Publishing House, 2006. 